\title{
1. Indigenous Peoples' Innovation and Intellectual Property: The Issues
}

\author{
Peter Drahos and Susy Frankel
}

\section{Introduction}

It is easy to find examples of international fora in which actors engage with the issues raised by the confluence of indigenous knowledge and intellectual property. A list would include the Convention on Biological Diversity (CBD), the Food and Agriculture Organization (FAO), the International Union for the Protection of New Varieties of Plants, the United Nations Educational Scientific and Cultural Organization (UNESCO), various UN human rights bodies, the World Intellectual Property Organization (WIPO) and the World Trade Organization (WTO). ${ }^{1}$

Intellectual property and indigenous knowledge are concepts that for a long time travelled separate historical pathways. Intellectual property (IP) is a generic term for systems of positive law, some of which, such as patent law, have medieval origins and some, such as integrated circuits law, that are of comparatively recent origin. A definition by extension would include copyright, database protection, designs, geographical indications, integrated circuits protection, plant variety protection, patents, trade marks, trade secrets, and actions in passing off or unfair competition (the nature and titles of which will vary between jurisdictions). These different systems are grouped together because they grant exclusive rights of ownership in abstract objects such as signs, algorithms and gene sequences. ${ }^{2}$ Indigenous knowledge is a much older phenomenon than IP, but it has existed as a concept within Western scholarship for only a short time, previously being most closely linked to anthropology and emerging as a distinct concept in the 1980s. ${ }^{3}$

The intersection of indigenous knowledge and IP comes about because of a number of factors, including the creation by indigenous people of global

\footnotetext{
1 For a full discussion of the work of these organisations see C Antons, 'The International Debate about Traditional Knowledge, Traditional Cultural Expressions and Intellectual Property' in C Antons (ed), Traditional Knowledge, Traditional Cultural Expressions and Intellectual Property Law in the Asia-Pacific Region (Kluwer Law International, 2009) 39.

2 For the full theoretical account see P Drahos, A Philosophy of Intellectual Property (Dartmouth, 1996).

3 S B Brush, 'Indigenous Knowledge of Biological Resources and Intellectual Property Rights: The Role of Anthropology' (1993) 95 American Anthropologist 653, 659.
} 
political networks in the second half of the twentieth century, the recognition of the economic value of indigenous knowledge and the increasing activism of developing countries around international IP rights. The next section of this chapter focuses on this history in a little bit more detail, bringing out the way in which the international discussions around indigenous knowledge and IP have conceptually partitioned the protection of indigenous knowledge from the core issue of land rights justice - the very issue that led indigenous people to globalise networks of resistance to colonisation. The report of the New Zealand Waitangi Tribunal, published in 2011, is perhaps unique in that it recognises that mātauranga Māori (Māori knowledge) and rights in its intangible values are intimately connected to Māori relationship with the land and the environment. The report states:

Māori culture as we know it today is a creation of its environment... $[\mathrm{T}]$ he elements that make it distinctive in the world can be traced to the relationships kaitiaki [guardians] built up with the land, water, flora, and fauna of this place. In this way, the mauri, or inner wellbeing of land and water spaces, and the whakapapa [genealogy] of flora and fauna do not just serve to articulate the human relationships with these things; they are the building blocks of an entire world view and of Māori identity itself. They play a similar role to the core definers of Western culture such as the arts, democracy, the rule of law, and so forth. But while the more human-centred Western culture tends to define itself by reference to its own thought and labour, Māori culture relies on pre-existing, pre-human definers - mountains, rivers, plants, animals, and so on. Māori culture seeks to reflect rather than dominate its surroundings. That is why the relationship between humans and taonga species is a definer of Māori culture itself. It is a preoccupation of the body of distinctive Māori knowledge that today we call mātauranga Māori. ${ }^{4}$

The principal purpose of this chapter is to address the broad question of whether IP systems can serve indigenous innovation systems. To foreshadow our argument a little, indigenous innovation is often place-based innovation that is cosmologically linked to land and an indigenous group's relationship with that place, rather than to laboratories. Supporting indigenous innovation requires an integrated model of IP rights, real property, and traditional law and customs. That poses a challenge for Western legal traditions that have over a long period parsed property into finely grained taxonomies of real and personal property rights, the latter underpinning complex processes of securitisation in

4 Waitangi Tribunal Report, Ko Aotearoa Tènei: A Report into Claims Concerning New Zealand Law and Policy Affecting Māori Culture and Identity (2011) vol 1, ch 2, 115-116 ('WAI 262'). <http://www.waitangitribunal.govt.nz/news/media/wai262.asp> 
early, middle and late capitalism. ${ }^{5}$ In Australia, the High Court has recognised the spiritual dimension of Aboriginal native title, but has also made it clear that native title rights and interests do not constitute a separate system of IP for the control of cultural knowledge. ${ }^{6}$ Native title is not an institution of the common law, but its interpretive evolution does take place within the basic structure of Australia's statutory and common law property institutions. ${ }^{7}$ This considerably diminishes the prospect of Australian courts recognising a system of native title rights for the control of intangible property.

Indigenous or traditional knowledge (on the use of these terms, see section 4 below) is often said to have a dynamic quality, but there has been little explicit analysis of the features of indigenous innovation systems that presumably must be responsible for this dynamism. Instead the tendency is to conceive of indigenous knowledge, either explicitly or implicitly, as useful knowledge in propositional form. Innovation is often conceptualised in terms of firms developing new products and processes. ${ }^{8}$ The ethnobotanical records in Australia and New Zealand provide some examples of indigenous innovation that fit with this standard approach. For example, recorded interviews with Wagiman elders show that the Wagiman people developed products and processes. The leaves of the ironwood tree, for example, were used as a fish poison and the roots provided the basis for the production of a glue. ${ }^{9}$ Similarly, the Wagiman discovered a method for producing a damper from the seeds of cycas canalis (bush palm) that is suitable for long-term storage and has high food energy. ${ }^{10}$ Much is also known about the uses of New Zealand endemic plants and Māori uses of them. ${ }^{11}$ Harakeke (commonly called flax) is central to mātauranga Māori (Māori knowledge) and to traditional Māori life. It 'provides shelter, garments, fine fibre for weaving (muka), and powerful medicines for a multitude of ailments' ${ }^{12}$ Another example is manuka, a tree that is valued for numerous properties, including its oil and honey that has exceptionally high antibacterial properties. ${ }^{13}$ These properties have been investigated by Western scientists ${ }^{14}$ and utilised in many business ventures.

\footnotetext{
5 On property and the securitisation process see $\mathrm{J}$ Braithwaite and P Drahos, Global Business Regulation (Cambridge University Press, 2000) 143.

6 On the spiritual dimension see Yanner $v$ Eaton (1999) 201 CLR 351. On the limits of native title as the basis for creating rights in intangibles see Western Australia $v$ Ward (2002) 213 CLR 1.

7 See Fejo $v$ Northern Territory of Australia (1998) 195 CLR 96, 128.

$8 \mathrm{C}$ Greenhalgh and M Rogers, Innovation, Intellectual Property, and Economic Growth (Princeton University Press, 2010) 4. On how IP rules relate to the decision to innovate see W van Caenegem, Intellectual Property Law and Innovation (Cambridge University Press, 2007).

9 L G Liddy et al, Wagiman Plants and Animals: Aboriginal Knowledge of Flora and Fauna from the Mid Daly River Area, Northern Australia (Department of Natural Resources, Environment and the Arts, NT Government and the Diwurruwurru-jaru Aboriginal Corporation, 2006) 39.

10 Ibid, 35.

11 See e.g. M Riley, Mãori Healing and Herbal (Viking Seven Seas NZ, 1994).

12 WAI 262, above $\mathrm{n} 4$.

13 Ibid, 128-131.

14 Ibid, 130, see explanation of the isolation of the active ingredients by German scientist.
} 
If we think of indigenous knowledge in terms of useful propositions, then it follows naturally — at least for lawyers - that one can ask and answer the question of whether a given item of propositional knowledge falls within the scope of protection of one or more IP systems. Detailed rule-based analyses of the various individual IP systems show that some systems, especially copyright, have some utility for the protection of traditional knowledge. ${ }^{15}$ However, the limitations of those systems are precisely why much of the discussion about the protection of indigenous knowledge has primarily developed in fora, such as the CBD and the FAO, which are not primarily concerned with IP. ${ }^{16}$

However, the focus of this book is not the on protection of indigenous knowledge propositionally conceived, but rather on the system of indigenous innovation that is responsible for the Wagiman people, for example, producing new products and processes. The generation of useful knowledge and techniques implies a set of institutions working in convergent ways to produce innovation. ${ }^{17}$ A systems perspective on innovation requires one to look more broadly at the institutions that contribute to innovative performance, as well as the distinctive linkages and interactions amongst institutional actors that characterise an innovation system. ${ }^{18}$ In the context of modern economies, this usually involves an examination of the linkages amongst firms and their industrial research laboratories, universities and government laboratories, as well as an examination of the role of institutions such as tax and venture capital markets. ${ }^{19}$ In the case of indigenous innovation systems, there will obviously be a different set of institutional linkages, including linkages amongst cosmological institutions, sacred sites and kinship systems. These linkages may extend to Western scientists working within a framework that is compatible with indigenous peoples' expectations (for an example, see Chapter two). The fifth section of this chapter suggests some institutional features of indigenous innovation, but this part of the analysis should be seen as preliminary. The analysis draws on the studies of Aboriginal people from Australia and Māori in New Zealand. Institutions of indigenous innovation are highly context dependent and less susceptible to the kind of harmonising influences of globalisation that have brought about

15 See e.g. T Janke and R Quiggin, 'Indigenous Cultural and Intellectual Property and Customary Law' (Background Paper 12, Law Reform Commission of Western Australia, 2005) <http://www.lrc.justice.wa.gov. $\mathrm{au} />$ See also S Frankel, 'Trademarks and Traditional Knowledge and Cultural Intellectual Property Rights' in G B Dinwoodie and M D Janis (eds), Trademark Law and Theory: A Handbook of Contemporary Research (Edward Elgar, 2008) 433 for discussion of the utility of trade mark law in protecting indigenous knowledge that is sometimes manifest in trade marks.

16 One exception is perhaps the negotiation in the World Intellectual Property Organization discussed in several chapters in this book.

17 On institutions and a theory of useful knowledge see J Mokyr, The Gifts of Athena: Historical Origins of the Knowledge Economy (Princeton University Press, 2002).

18 R R Nelson, 'National Innovation Systems: A Retrospective on a Study' (1992) 1 Industrial and Corporate Change 347.

19 For examples of this approach see ibid; P A Hall and D Soskice (eds), Varieties of Capitalism: The Institutional Foundations of Comparative Advantage (Oxford University Press, 2001). 
the institutional convergences that we see taking place in capitalist innovation systems. This sets limits on the extent to which one can generalise about them. A full institutional analysis of indigenous innovation is an interdisciplinary quest in which a number of disciplines, including ethnobotany, cognitive anthropology and human ecology, play a crucial role. ${ }^{20}$

The primary purpose of this chapter is to bring into focus a distinction between indigenous knowledge and indigenous innovation, and then to identify some of the institutional characteristics of the latter. Following on from this, the last section of the chapter discusses which systems of IP are likely to best support systems of indigenous innovation. Other chapters in this book also explore this issue. This is a different question from asking which items of propositional knowledge are most effectively protected by which IP rules. A patent may represent the best fit between an active ingredient derived from a plant and the indigenous group with traditional rights over the plant, but it does not follow that the patent system is the best system for the innovation system of people of which that group is a part.

\section{The Search for Justice: From Individuals to Global Indigenous Networks}

When European states colonised countries, the land ownership systems of the original inhabitants of those countries generally underwent a radical transformation $^{21}$ or, as in the case of Australia, were extinguished altogether. ${ }^{22}$ Unable to find land rights justice within settler societies, some indigenous groups from countries such as Australia, Canada and New Zealand took their cause to seats of power in Europe. For example, delegations of Māori travelled to England in 1882, 1884, 1914 and 1924 in an attempt to meet with monarchs. ${ }^{23}$ Among the petitions organised by the Aboriginal leader William Cooper was a petition of 1937 addressed to King George V. It contained 1,814 signatures of Aboriginal people, and asked for Aboriginal representation in the Australian

\footnotetext{
20 For a discussion of the contribution of these disciplines see Brush, above n 3; P Sillitoe, 'The Development of Indigenous Knowledge: A New Applied Anthropology' (1998) 39 Current Anthropology 223; F Berkes, Sacred Ecology (2nd ed, Routledge, 2008) 22.

21 For a study of Crown Māori land policy and practice in the period 1869-1929, see R Boast, Buying the Land, Selling the Land: Governments and Māori Land in the North Island 1865-1921 (Victoria University Press, 2008). 22 More than 200 years later this was found to be the wrong view of the law. The Australian High Court in its famous Mabo decision found that the reception of British law into Australian colonies did not produce the chain of extinguishment supposed by colonial legal authorities. See Mabo v Queensland [No 2] (1992) 175 CLR 1 ('Mabo').

23 See D Sanders, 'The Formation of the World Council of Indigenous Peoples' (Fourth World Documentation Project, Center for World Indigenous Studies, 1980) <http://cwis.org $>$
} 
Parliament. ${ }^{24}$ In 1923 Deskaheh, a chief of the Cayuga, travelled to the League of Nations as a spokesman for the Six Nations of the Iroquois League. ${ }^{25}$ In essence he wanted the League of Nations to help the Iroquois League gain the sovereign independence and territory that had been agreed to by King George III but was now opposed by the Canadian Government. Anthony Fernando, whose mother was Aboriginal, left Australia for Europe in the early 1900s. Deported from Italy to Britain in 1923 for distributing pamphlets declaring the extermination of indigenous people by the British in Australia, he spent his days in England in sole protest, at one stage regularly appearing outside Australia House in London in a coat covered with toy white skeletons. ${ }^{26}$ The skeletons, he said, depicted the fate of his people.

These and other attempts like them generally ended in failure. The Australian authorities never forwarded Cooper's petition. Deskaheh left Geneva without success, and died alone in New York in 1926. Fernando died in a mental hospital in Essex in 1946.

Indigenous people nevertheless persisted with the strategy of globalising their fight for justice. The evolution of the UN system, which began with the United Nations Charter of 1945, created new opportunities for them. The language of human rights treaties seemed full of evocative promise: All peoples have the right of self-determination' (Article 1.1 of the International Covenant on Civil and Political Rights). The indigenous networks of political mobilisation and negotiation that evolved around indigenous peoples' issues concentrated on developing a broad rights-based agenda at the highest levels of international law-making. ${ }^{27}$ However, IP remained a technically obscure subject and there was little understanding of its connections with indigenous knowledge systems. This, as the next section makes clear, began to change slowly in the 1980s.

\section{Enter Developing States}

After World War II many developing countries became sovereign states. One of the consequences of this particular wave of decolonisation was that developing states began to press for the reform of the international IP framework.

\footnotetext{
24 Cooper's story is told in B Attwood and A Markus, Thinking Black: William Cooper and the Australian Aborigines' League (Aborigines Studies Press, 2004).

25 J Rostkowski, 'The Redman's Appeal for Justice: Deskaheh and the League of Nations' in C F Feest (ed), Indians and Europe: An Interdisciplinary Collection of Essays (University of Nebraska Press, 1989) 435.

26 Fernando's story can be found in the Australian Dictionary of Biography. See <http://adbonline.anu. edu.au/biogs/AS10160b.htm > For a more detailed account see F Paisley, 'Australian Aboriginal Activism in Interwar Britain and Europe: Anthony Martin Fernando' (2009) 7 History Compass 701.

27 R Niezan, 'Recognizing Indigenism: Canadian Unity and the International Movement of Indigenous Peoples' (2000) 42 Comparative Studies in Society and History 119. See also C Charters, 'A Self-Determination Approach to Justifying Indigenous Peoples' Participation in International Law and Policy Making' (2010) 17 
These reform attempts, which became part of a broader and deeper push during the 1970s for a New International Economic Order, ultimately failed. ${ }^{28}$ Moreover, during the 1980s developing countries came under trade pressure from the US to comply with standards of IP protection that favoured US export interests. ${ }^{29}$ Developing countries also found themselves having to defend against moves by the US and EU to bring IP standards into the Uruguay Round of multilateral trade negotiations that had begun in 1986. Developing country attempts to defeat this US and EU agenda also failed.

The issue of indigenous knowledge and IP remained in the shadows. It gained some limited recognition in the publication of the Tunisian Model Copyright Law in $1976 .{ }^{30}$ This law recognises copyright in works of national folklore, a concept that has some overlap with indigenous knowledge. ${ }^{31}$ Two events in the early 1990s helped to bring about the convergence of IP and indigenous knowledge as part of the formal work programmes of international organisations. The CBD, which came into force in 1993, expressly recognises the importance of indigenous and local knowledge to the conservation and sustainable use of biodiversity. The field of ethnobiology had grown during the 1980s, and more international organisations had established research programmes on indigenous knowledge. ${ }^{32}$ Its value, both economic and non-economic, was slowly gaining recognition. The other event was the inclusion of the Agreement on TradeRelated Aspects of Intellectual Property Rights (TRIPS) in the package of Uruguay Round agreements that were signed by states in 1994.

The 1990s saw a complex negotiating agenda evolve amongst states within the WTO and the CBD around the issues of the patentability of biological materials and the protection of traditional knowledge (the term that came to be preferred to indigenous knowledge). International legal instruments have dissected traditional knowledge into that related to biological materials and that more directly connected to works of art and culture. The latter has acquired the terminology traditional cultural expressions. ${ }^{33}$ The division of traditional knowledge into these categories reflects a categorisation analogous to that found in IP law. Copyright and expressive uses of trade marks are analogous to traditional cultural expressions, and biological materials are associated with patents and

\footnotetext{
28 For the history see S K Sell, Power and Ideas: North-South Politics of Intellectual Property and Antitrust (State University of New York, 1998).

29 P Drahos and J Braithwaite, Information Feudalism: Who Owns the Knowledge Economy? (Earthscan, 2002) 99.

30 D Zografos, Intellectual Property and Traditional Cultural Expressions (Edward Elgar, 2010) 14.

31 Berne Convention for the Protection of Literary and Artistic Works (Paris Act, 1971) 1161 UNTS 18388, art 15(4) recognises folklore as copyright works. The recognition is not dependent on identification of the exact author as other copyright protection under the Convention is. However, this is not the same as recognition of indigenous knowledge on its own terms; rather it is recognition that it might in some circumstances be protected as copyright.

32 Berkes, above n 20, 21-22.

33 The chapter by Daphne Zografos Johnsson in this book discusses that terminology.
} 
plant variety rights. The concept of traditional knowledge transcends both. This sort of categorisation does not necessarily reflect the ways in which indigenous peoples see their knowledge. It is no coincidence that biological materials that are important to Māori, for example, are frequently found in works of art and in carvings on or within buildings. Representations of the distinctive blooms of the kōwhai ngutukākā plant are found in the wharewhakairo (carved house) at Te Pakirikiri marae. The same representations are also found on Ruatepupuke, a meeting house located in the Field Museum in Chicago. ${ }^{34}$

The CBD makes it clear that states have sovereignty over their biological resources. ${ }^{35}$ It also requires access to genetic resources to be based on prior informed consent and the fair and equitable sharing of benefits from those resources. ${ }^{36}$ Patents are, as TRIPS recognises, available for inventions, but not for discoveries. Naturally occurring biological resources are not patentable, but can be converted into inventions, often through a minimal technical step of isolation and purification. ${ }^{37}$ The conversion of raw biological materials to be found in nature into an invention through some minimal intervention can be seen as the patent system allowing a form of selective free riding. Further, as we will see in section five of this chapter, the idea of raw biological materials existing in nature awaiting conversion into inventions by patentees is deeply problematic from the perspective of indigenous innovation. As we will see, indigenous people in Australia were managing the land with a view to improving the biological materials to be found in it. The biodiversity that confronted arriving colonists was not that of nature in raw form, but rather the many products of the land that had resulted from thousands of years of intervention and management of that land by indigenous people.

During the early 1990s non-state actors began to point to the unfairness of this selective free-riding effect, characterising it as 'biopiracy'. ${ }^{38}$ Many developing states also began to argue that TRIPS undermines the CBD because it requires all WTO members to allow for the patentability of micro-organisms and microbiological processes and the protection of plant varieties (by means of patents or some other system, or some combination thereof). ${ }^{39}$

\footnotetext{
34 WAI 262, above n 4, 123-124.

35 See para 4 of the Preamble, arts 3 and 15.1 of the CBD.

36 See arts 15.5 and 15.7 of the CBD.

37 For a comprehensive history and analysis of the way in which the distinction between invention and discovery has been subverted in patent law see L Palombi, Gene Cartels: Biotech Patents in the Age of Free Trade (Edward Elgar, 2009).

38 D F Robinson, Confronting Biopiracy: Challenges, Cases and International Debates (Earthscan, 2010) 14.

39 The negotiations in the WTO over the relationship between the CBD and TRIPS date back to the late 1990s. There are a very large number of documents. For a summary of the many views of different coalitions of states, including the view that TRIPS undermines the CBD, see WTO Secretariat, The Relationship between the TRIPS Agreement and the Convention on Biological Diversity: Summary of Issues Raised and Points Made, WTO Doc IP/C/W/368/Rev.1 (2006).
} 
A similar kind of selective free-riding argument can be developed around the use of indigenous knowledge. In those cases where indigenous groups have maintained their institutions they will, under their customary law systems, be able to identify who has ownership and use rights over knowledge. However, whether they have IP in that knowledge depends on the application of specific rules of protection to be found in the relevant IP system. Under these systems, an owner of the indigenous knowledge may not be found because, for example, IP systems do not recognise an ancestor as a legal person or because the knowledge is regarded as having entered the public domain. There is, however, considerable evidence that the willingness of indigenous peoples to share their knowledge is not, from their perspective, the equivalent of placing it in the public domain. ${ }^{40}$ TRIPS does not set standards of protection that are specific to indigenous knowledge, but because it protects IP rights that utilise traditional knowledge, its impact on the holders of that traditional knowledge has been considerable. The CBD links the principle of equitable sharing of benefits to the use of traditional knowledge. ${ }^{41}$

TRIPS and the CBD catalysed the emergence of policy and activist networks around the issue of indigenous knowledge and IP. Definitional issues, as the next section shows, have loomed large for these networks.

\section{The Quicksands of Definition}

Law is obsessed with definition. Statutes, for example, frequently have a definitions section or an interpretation section. Without definitions, the discipline of law treats itself as undefined and uncertain. This has contributed to a plethora of definitions relating to traditional knowledge. Indigenous peoples do not usually attach the same value to abstract definition. If called upon to define their traditional knowledge, they will emphasise not the analytical facets of knowledge, but rather the relational boundaries and dynamics created by the possession of knowledge. This includes indigenous peoples' relationship with their knowledge, and their responsibility to maintain and develop the knowledge for the good of society and future generations. Māori, for example, are kaitiaki (guardians) of their knowledge. Additionally, being kaitiaki in part defines Māori culture and identity. ${ }^{42}$

\footnotetext{
40 S Frankel and M Richardson, 'Cultural Property and "the Public Domain": Case Studies from New Zealand and Australia' in C Antons (ed), Traditional Knowledge, Traditional Cultural Expressions and Intellectual Property Law in the Asia-Pacific Region (Kluwer Law International, 2009) 275.

41 See para 12 of the Preamble and art 8(j) of the CBD.

42 WAI 262, above n 4,115-118.
} 
The disciplines of cognitive anthropology and human ecology in particular have been important to recognising folk knowledge as systems of knowledge. ${ }^{43}$ At first the terms 'indigenous' and 'folk' were used interchangeably, and in contrast to formalised systems of scientific knowledge. A similar interchangeability of the terms is to be found in the study of legal systems, the contrast here being with codified or positive systems of law. ${ }^{44}$ As we noted in section 1 above, the concept of an indigenous knowledge system appears in anthropological literature in the early 1980s. Within anthropology, the term 'indigenous' comes to be linked to cases of distinct tribal groups involved in a rights struggle with a state not founded by those groups. ${ }^{45}$ The meaning of the term is thereby narrowed.

Within international law, the term 'indigenous' is open ended. The United Nations Declaration on the Rights of Indigenous Peoples (DRIP) avoids proposing a definition, stating that indigenous peoples 'have the right to determine their own identity or membership' ${ }^{46}$ Self-identification appears to be the core principle within the UN system for determining the application of the term. ${ }^{47}$ This devolutionary strategy may not always help. If being $\mathrm{X}$ depends upon a right of self-identification as $\mathrm{X}$, and this right is open to all, then it follows that anyone may make use of the right to become X. A potential political problem arises for states, because being indigenous gives access to a rights-based discourse in which the principle of self-determination features prominently. Within South-East Asia and South Asia some states such as India, Indonesia and Malaysia have attempted to characterise their population at large as indigenous and to avoid the use of the term as a descriptor for minority groups such as hill tribes. ${ }^{48}$ Moreover, in these regions, migration patterns, intermarriage and cultural cross-pollination make the ascription of indigenous to particular groups a matter of debate and complexity.

UN treaties tend to proliferate rather than restrict meanings in this field. The Indigenous and Tribal Peoples Convention of 1989 draws a distinction between tribal and indigenous people. Tribal people are linked to a group that selfregulates on the basis of custom, while indigenous people are those who existed as a group prior to an act of conquest or colonisation and have retained at least some of their pre-existing institutions. The CBD refers to 'indigenous and local

\footnotetext{
43 Brush, above n 3, 658-659.

44 See G C J J Van Den Bergh, 'The Concept of Folk Law in Historical Context: A Brief Outline' in A D Renteln and A Dundes (eds), Folk Law: Essays in the Theory and Practice of Lex Non Scripta (University of Wisconsin Press, 1994).

45 Brush, above n 3, 658 .

46 For an indigenous peoples' discussion of the Convention see L Malezer, C Charters and V Tauli-Corpuz (eds), Indigenous Voices: The UN Declaration on the Rights of Indigenous Peoples (Hart Publishing, forthcoming).

47 United Nations Development Group, Guidelines on Indigenous Peoples' Issues (2009) 9.

48 G A Persoon, "'Being Indigenous" in Indonesia and the Philippines' in C Antons (ed), Traditional Knowledge, Traditional Cultural Expressions and Intellectual Property Law in the Asia-Pacific Region (Kluwer Law International, 2009) 195, 196.
} 
communities'. Negotiations within WIPO are aimed at producing an international instrument of some kind to protect traditional knowledge. The current draft articles take the form of alternative options. ${ }^{49}$ The term 'traditional knowledge' is preferred to 'indigenous knowledge'. The draft options use different terms such as 'indigenous people', 'local communities' and 'traditional communities'. It is anyone's guess what the final form of the international instrument will be.

Traditional knowledge is perhaps the most open-ended concept that one might choose in this field. Some knowledge, argues Polanyi, cannot be specified by means of rules and can be passed on only through relationships of close learning such as master and apprentice..$^{50}$ This form of personal knowledge depends on tradition. All societies, including capitalist societies, have traditional knowledge.

Not surprisingly, a range of definitions of traditional knowledge has emerged from the literature. ${ }^{51}$ Traditional knowledge is sometimes linked to environmental or ecological knowledge, or to local knowledge held by groups such as farmers and fishermen (who may or may not be indigenous). Other definitional strategies include contrasting traditional knowledge with scientific knowledge, or specifying key properties for it such as oral transmission and its embeddedness in a non-materialist cosmology. All definitional strategies run into problems of one kind or another. For example, the contrast with science can be overplayed, as both traditional knowledge systems and science depend on the making of observation statements and testing. Returning to our earlier examples of the Wagiman people's knowledge of the calorific and storage properties of damper made from the bush palm, and of Māori knowledge of the properties of harakeke, it is clear that this kind of knowledge must have involved a process of observation and experimentation.

Trying to confine traditional knowledge to a class of knowledge (for example, ecological knowledge) or a class of people is very difficult. The reason that legal definitions place an emphasis on a determinate class of people is not necessarily related to the role that knowledge plays in a society, or even what constitutes knowledge, but rather it is to attribute rights, or ownership, to that class of persons. However, the value of indigenous knowledge sometimes arises because of the fact that it is attributable to an open-ended class, as in the case of the inter-generational development of plant knowledge: it has a proven pedigree.

Traditional knowledge is a potentially widespread phenomenon. For example, Mansfield's study of US companies and their foreign direct investment strategies

49 WIPO's work, as well as draft text aimed at protecting traditional knowledge, traditional cultural expressions/folklore and genetic resources, can be found at <http://www.wipo.int/tk/en/igc/index.html $>$

50 M Polanyi, Personal Knowledge: Towards a Post-Critical Philosophy (Routledge \& Kegan Paul, 1958) 53.

51 For a survey see G Dutfield, 'Legal and Economic Aspects of Traditional Knowledge' in KE Maskus and JH Reichman (eds), International Public Goods and Transfer of Technology Under a Globalized Intellectual Property Regime (Cambridge University Press, 2005) 495. 
revealed, amongst other things, that pharmaceutical company employees had personal knowledge about chemical processes that their employer companies held back as part of their licensing strategies. ${ }^{52}$ Intimate knowledge about what makes a complex chemical process work optimally fits within Polyani's concept of personal knowledge, and is exactly the kind of knowledge that is passed on through personal training. It is a form of traditional knowledge. In the context of an international negotiation, the fact that the concept of traditional knowledge has an ever-expanding penumbra of meaning provides states which are minded to do so with numerous opportunities to exploit the uncertainty of the concept and thus slow down the negotiations of any treaty dealing with the concept.

Continuing on with our Wagiman example, both scientists and the Wagiman people can agree on the properties of the bush palm, and both will have made use of observational methods and testing in arriving at their knowledge of those properties. However, if we were to give a full specification of the pathway to discovery along which the Wagiman people travelled, we would find it is made up of different institutions from those on the pathway travelled by scientists. The institutions making up the Wagiman people's pathway might include a totemic system of classification in which the identity of some individuals is linked to the bush palm, as well as a cosmological system in which the bush palm features as a totemic ancestor. By shifting the focus onto an indigenous innovation system we can begin to ask about the institutions that form the discovery pathway in that system and that need to be supported for the pathway to remain open. IP systems may have a supportive function for an indigenous innovation system, but without a clear analysis of the institutions that make up this system we will not be able to work out which IP systems matter to this function. And once we embark on an institutional analysis of indigenous innovation we will also gain a better understanding of where IP sits in the lists of priorities for the support of indigenous innovation. In the case of Aboriginal people in Australia, the place-time nature of their system means that land rights justice is the primary necessary first step..$^{53}$

Land rights justice, although not completely resolved, is considerably closer to having been achieved in New Zealand through the Waitangi Tribunal and Treaty settlement process. That may be one reason why Māori were able to bring the WAI 262 claim concerning the protection of their knowledge, culture and identity to the Waitangi Tribunal. ${ }^{54}$ This claim shows how progress on land rights justice opens the way to progress on the protection of indigenous knowledge and culture more broadly.

52 E Mansfield, 'Intellectual Property Protection, Foreign Direct Investment, and Technology Transfer' (Discussion Paper 19, International Finance Corporation, The World Bank, 1994).

53 There is a broader question about whether IP can achieve much for the poor in developing countries in the absence of land reform. See D Rangnekar, 'The Challenge of Intellectual Property Rights and Social Justice' (2011) 54 Development 212. 
An institutional approach also shows that support for indigenous innovation will require a multi-level governance approach. The global level of governance is the right level at which to be discussing the possibility of a treaty-based misappropriation norm for traditional knowledge, but at the state level of governance there are clearly many more issues — such as land rights and access to capital - that must be addressed if states genuinely want to support indigenous innovation.

\section{Indigenous Innovation}

Indigenous innovation is place-based innovation. In the case of Aboriginal people in Australia, it takes place on 'Country', a term we explain a little later. It is the place where the people observe and interact with the plants and animals to which they are cosmologically linked in some way. Their Country is their laboratory. The focal point of Māori innovation is also place. Rights over resources, and obligations such as that of being kaitiaki, are made concrete by being part of a group that is related to a place and is itself integrated into a network with human and non-human members (for example, the plants, animals, rivers of that place). It is this place-based network that maintains and advances knowledge. Individuals can, of course, leave the place of their spiritual affiliation and connection (their Country) but remain part of a network, communicating with its other members and contributing to its production of knowledge. Place anchors indigenous networks of innovation, but these networks can and usually do extend beyond place.

To expand the claim that indigenous innovation is place-based innovation, we need to outline the place-time cosmology that underpins this innovation system. Indigenous Australians have distinct and systematised beliefs about the true nature of the universe. These beliefs continue to exercise a profound influence on Aboriginal social organisation, including the organisation of indigenous knowledge and innovation systems. The term 'cosmology' does a better job of communicating the idea that these beliefs are thought to be true of the world than do the English words 'Dreamtime' or 'Dreaming'. The use of Dreamtime goes back to a mistranslation of a word from the Aranda language that is better translated as 'eternal, uncreated, springing out of itself' ${ }^{55}$

In the broadest terms, these cosmologies deal with a class of eternal events involving ancestral beings that remain present in a place. ${ }^{56}$ One of the features

\footnotetext{
55 T Swain, A Place for Strangers: Towards a History of Australian Aboriginal Being (Cambridge University Press, 1993) 21.

56 For more detailed discussions see H Morphy, Ancestral Connections: Art and an Aboriginal System of Knowledge (The University of Chicago Press, 1991); Swain, above n 55; F Dussart, The Politics of Ritual in an Aboriginal Settlement (Smithsonian Institution Press, 2000).
} 
of Aboriginal cosmologies is their focus on explaining the origins of the physical features of particular areas of the country. ${ }^{57}$ In these cosmologies ancestral beings in either animal or human form will often begin a journey in a specific place and end it in another known place. Along the way they will, through the exercise of their great powers, transform the landscape to give it the physical features by which it is known today. Through their geo-magical powers, the ancestors create the topography of an area that clan members come to know as their 'Country'. Ancestors also leave behind a landscape that is more propitious for the survival of its inhabitants. There are waterholes and freshwater springs, names to help classify animal and plant life, as well as useful tools such as fish traps and many other things. The features of the landscape are evidence of the ancestors' travels, with ancestors sometimes leaving behind personal signs such as footprints or bodyprints on cave walls.

Aboriginal cosmology is not one cosmology made up of an abstract set of truths in the canonical form of a text or set of equations. Rather it is many cosmologies that speak of great events, events that are made concrete because they are embodied in Country. There is no need for written records or archives because the land itself holds and displays to the trained knower all the knowledge that matters. The land is a living and signalling embodiment of knowledge. Prior to the arrival of mining and agricultural technologies, the land would have seemed to indigenous people to be the most permanent presence of knowledge imaginable. The details of this knowledge are poetically encrypted in stories, and transmitted through dance, singing, ritual and story-telling.

Country is an emotional centre of being. It is a place that one knows intimately at many levels, and in which one has countrymen and rights along with the safety and security that these things bring. It is where one can truly 'sit down'.$^{58}$ Cosmologies and Countries are indissolubly linked. Different groups of ancestors have shaped different areas of land in Australia. Exceptionally powerful totemic beings such as the Rainbow Serpent feature in more than one cosmology, but the stories in which they feature are not the same story. Ancestral beings are, as it were, local rather than universal forces. It follows, for example, that a Lardil person from Mornington Island who goes to central Australia where the Warlpiri live is not equipped, by virtue of Lardil cosmology, to understand the forces that shaped Warlpiri country.

57 I Keen, Aboriginal Economy and Society: Australia at the Threshold of Colonisation (Oxford University Press, 2004) 211.

58 D McKnight, People, Countries, and the Rainbow Serpent (Oxford University Press, 1999) 81. 
Māori innovation is also in many ways place based. This is captured in many parts of the Ko Aotearoa Tenei: A Report into Claims Concerning New Zealand Law and Policy Affecting Māori Culture and Identity (WAI 262), and some of those passages are best quoted:

In the 1,000 years or so in which Māori have lived on the islands of Aotearoa, they have developed - among countless other things artistic and cultural traditions that are uniquely of this place. The underpinnings of these traditions are found in the environment itself mountains, rivers, sea and sky, plants and animals - and their expression takes many forms, ranging from the architectural achievements of the great meeting-house and canoe builders, to the works of weavers, carvers, tohunga tā moko, musicians, and the like, as well as in te reo Māori, the language itself. These works, founded in and reflecting the body of knowledge and understanding known as mātauranga Māori, are what we call taonga works. Some of them are ancient, others not, but those who are responsible for safeguarding them, whether or not they are the original creators of the works, have a very particular relationship with them. We call this the kaitiaki relationship. ${ }^{59}$

The people who arrived in Aotearoa from Hawaiki some 1,000 years ago embedded themselves in the new environment, changed it, and were in turn changed by it. Nowhere were these changes more evident than in technology and the arts. They reflected the incremental development of a new and unique culture. New technologies were required to cultivate, hunt, and gather food. New stories and traditions had to be built up to explain to succeeding generations why some methods worked and others didn't, and why some behaviours were good and others not. Methods had to be invented to cultivate and store canoe crops such as taro and kūmara in a climate that permitted only one planting cycle per year, and traditions were required around those methods to ensure adherence to conduct most likely to produce a successful harvest. Unfamiliar plants were tested for their utility as food, medicine, fibre, or building material, and then catalogued within an entirely newly constructed whakapapa (genealogy). As in Hawaiki, this whakapapa had then to be given texture and meaning through story and tradition that explained relationships. These relationships helped to ensure that the integrity of the catalogue could be maintained in memory, and they explained the value (and the dangers) of each species, as well as inter-species compatibility. Birds, fish, and shellfish were tested and ordered in the same way. This time whakapapa, supplemented by story and song, would explain habitat, growth cycle, sensitivity to environmental change, and edibility. ${ }^{60}$ 
If there is one thing that unites indigenous systems of knowledge it is the principle that most or all knowledge that is part of a group's system can be traced back to the acts of powerful ancestors. The acts of ancestors are the threads that connect different parts of an indigenous knowledge system. One can, for example, give independent descriptions of a group's botanical taxonomies, but the ultimate origins of these taxonomies lie in the names and classifications that ancestral spirits created along with the landscape and the animals and plants in it. Indigenous knowledge systems are said to be holistic, but we prefer the term 'connectionist', which better captures the densely networked way in which indigenous people in Australia and New Zealand perceive the world.

Indigenous people are born into social systems that, from the very beginning, multiply the number of connections that make up their world. Their kinship system links them to places for which they have duties as custodians and guardians, as well as to the places of other groups (primarily through intermarriage), their ancestors and the events associated with those ancestors. Aboriginal societies are sometimes described as kinship societies because no individual of a given tribe is left out of a kinship calculation. ${ }^{61}$ Kinship is foundational in Māori society. In the words of the Ko Aotearoa Tenei, kinship is 'a revolving door between the human, physical, and spiritual realms' ${ }^{62}$

In this connectionist world plants, animals, rocks, rivers and other things have multidimensional natures. A tree may have utilitarian functions, such as providing shelter and being a source of medicine, but it may also be linked to a person by virtue of a kinship relation because, for example, it features in an ancestral story on that person's mother's side, leading that person to say that 'this tree is my mother' ${ }^{63}$ From this kinship connection there may flow a set of rights and obligations with respect to a tree species. A very large range of things can function as a totem, including plants, animals, wind, rain, thunder, fire, mist, tools and food, as well as parts of the human body. ${ }^{64}$

We can see even from this brief description that indigenous individuals are immersed in a social network that stretches well beyond the conventional understanding of a social network, because the units of the network include plants and animals and the land itself: 'The people of a place are related to its mountains, rivers and species of plant and animal, and regard them in personal terms. ${ }^{65}$ Connectionism refers to the fact that traditional knowledge systems are part of social networks that are characterised by variety in the types of

61 McKnight, above n 58, 33.

62 WAI 262, above $\mathrm{n} 4,13$.

63 I Keen, Knowledge and Secrecy in an Aboriginal Religion (Clarendon Press, 1994) 107.

64 W E H Stanner, White Man Got No Dreaming 1938-1973 (Australian National University Press, 1979)

106, 127-129.

65 WAI 262, above n $4,17$. 
units in the network, as well as density of connections amongst those units. The density of connection comes about because communication with the non-human members of the network is seen as possible. Indigenous cosmology, kinship systems and totems operate together to create a complex web of relations that for the most part remains opaque to outsiders.

Before we move on to discuss other features of indigenous innovation, it is important to note that states participating in international discussions of traditional knowledge and IP have conceptually partitioned IP issues from land rights issues. The WAI 262 claim explicitly recognises and articulates the importance of the connection to the land and the way in which the relationship with the land impacts Māori culture and identity. ${ }^{66}$ International organisations like the WIPO and the WTO focus on IP issues raised by traditional knowledge, but stay silent about traditional land rights. Of course, this is exactly what the member states of these international organisations want, but it is a partition that makes no sense to indigenous people. Their knowledge systems are deeply rooted in the place-time relations of land. To protect the former, one must recognise rights to the latter.

As we have shown, placed-based innovation is integrated with a connectionist cosmological scheme in which knowledge is generated as part of a web of relations that include ancestors and totemic entities. As one might expect of ancient cultures that innovate under conditions of cosmological connectionism, many rules and restrictions concerning the use of knowledge have evolved.$^{67}$ Indigenous systems of governance for knowledge and innovation do not really accommodate the concept of unrestricted public domain rights that characterise some IP systems. ${ }^{68}$ The expiry of patent and copyright terms sees information enter the public domain for use by competitors. Within indigenous knowledge systems, those with custodial rights over land, plants or animals and the knowledge related to those things do not hold those rights for a limited time. Potentially this sets up a problem of access to vital resources in indigenous societies, and so others are given use rights over resources held by primary custodians. ${ }^{69}$ Kinship relations will be a determining factor in the kind of use rights a given individual can gain. In essence, IP systems and indigenous governance systems solve access problems to resources in different ways. IP systems, with some exceptions such as trade secrets and trade marks, make protection time-sensitive, while indigenous systems place the emphasis on use rights. In the former, exclusivity of use is offset by limiting the duration

\footnotetext{
66 Ibid.

67 For examples see Morphy, above n 56, 89.

68 K Bowery, 'Indigenous Culture, Knowledge and Intellectual Property: The Need for a New Category of Rights?' in K Bowery, M Handler and D Nicol (eds), Emerging Challenges in Intellectual Property (Oxford University Press, 2011) 46, 47.

69 For examples of use rights see Keen, above n 57, ch. 9.
} 
of exclusivity, while in the latter case perpetual rights are offset by granting use rights to others. Interestingly, in the case of the perpetual rights allowed by systems of trade secret protection and trade marks one can see use-right solutions being employed to deal with access issues. For example, trade secret protection does not prevent a third party from using information that the party has discovered independently of the trade secret holder.

Another feature of indigenous innovation is the strong presence of uncodified knowledge. The information theoretic perspective on innovation draws a distinction between codified and uncodifed information, with the latter being best transferred by means of personal communication..$^{70}$ A subset of uncodified information may also be uncodifiable in that it cannot be captured by rules. As Polanyi argues, the transmission of such knowledge depends on personal teaching and tradition.

A good example of the role of personal knowledge in indigenous innovation is to be found in techniques of fire management. In Arnhem Land, Australia, there are areas of land that have been in the hands of traditional custodians for many decades, allowing those custodians to use a traditional system of fire management. ${ }^{71}$ In outline, this system is based on a seasonally based method of burning. Burning begins in the early dry season, and is first targeted on the higher parts of Country where the moisture content of the grass — which acts as a natural control on the extent of the burn - has fallen. Burning continues throughout the dry season, moving into lower areas and reaching a peak in the coolest months of the dry season. As groups move about and carry out burning on their Countries, a mosaic pattern of burnt and unburnt patches develops. The essence of the method is to produce a large number of smaller, cooler fires that pose less risk for people and Country.

Achieving a 'cool burn' that causes minimal damage to trees and insect life, but at the same time stimulates grasses to the right level of re-growth, requires an intimate knowledge of how to manage the fire, as well as judgement about exactly the right time and conditions under which to burn. The mosaic method of burning requires supervision by masters of the method. It is not a matter of just strolling into the bush and randomly setting bits of it alight. Standing in the bush watching an indigenous man calmly and deliberately start a series of fires that culminate in a racing wall of flame makes one realise how much depends on accurate judgement about exactly when to start the fire so that it will run and stop in a predictable way. ${ }^{72}$

70 T Mandeville, Understanding Novelty: Information, Technological Change, and the Patent System (Ablex Publishing Corporation, 1996) 50.

71 D Yibarbuk et al, 'Fire Ecology and Aboriginal Land Management in Central Arnhem Land, Northern Australia: A Tradition of Ecosystem Management' (2001) 28 Journal of Biogeography 325.

72 Drahos was a participant in the Indigenous Fire Workshop Program, 12 July 2010 to Friday 16 July 2010. The workshop was hosted by the Chuulangun community which is based at Chuulangun on the upper Wenlock River, Northern Queensland. 
The ecological value of this innovative technique has slowly been scientifically understood. The technique helps to avoid the highly destructive large-scale fires that are typical of late-season fires in Northern Australia. ${ }^{73}$ One study of an indigenous estate in north-central Arnhem Land on which this traditional method of burning had been more or less continuously used to the present time showed that the method promoted ecological integrity as measured by a number of indicators such as biodiversity, and the presence of rare native fauna and threatened fire-sensitive vegetation types. ${ }^{74}$

The rights of Māori to some kind of control over waterways has been recognised in New Zealand as part of Māori rights under the Treaty of Waitangi. This has led to co-management structures to achieve, amongst other things, conservation and sustainable environment goals. In 2010 the Cabinet formed a new policy, 'Involving Iwi ${ }^{75}$ in Natural Resource Management through Historical Treaty of Waitangi Settlements'. ${ }^{76}$ As well as having the goal of settling grievances between Māori and the Crown, the aim of the policy is to enable iwi to have an effective role in natural resource management, and to create good 'environmental, economic, social and cultural outcomes for iwi and other New Zealanders'. Co-management can take many forms, ranging from consultation through to decision-making powers for Māori. One commentator has described co-management as 'knowledge sharing'. ${ }^{77}$

The level of Māori control in a co-management arrangement depends on the particular Treaty settlement that Māori have negotiated, or the arrangements they have made with the local council or that are required under the Resource Management Act. ${ }^{78}$ Co-management arrangements are about far more than the settlement of grievances or the avoidance of future grievances. It is increasingly recognised that iwi have, both in the past and present, taken good care of New Zealand's great outdoors where they have been permitted to do so. The approach of Māori to the environment, and their techniques for managing resources, contribute to the conservation and sustainability goals of government. The Māori approach is a reflection of the relationship between the people and the environment, and the interconnectedness of people, the land, and the flora and fauna. What creates sustainable practices is the belief that if you harm one aspect

\footnotetext{
73 J Russell-Smith et al, 'Challenges and Opportunities for Fire Management in Fire-prone Northern Australia' in J Russell-Smith, P Whitehead and P Cooke (eds), Culture, Ecology and Economy of Fire Management in North Australian Savannas: Rekindling The Wurrk Tradition (CSIRO Publishing, 2009) 1.

74 Yibarbuk et al, above $\mathrm{n} 71$.

75 Iwi is the Māori word for tribal group.

76 Office of Treaty Settlement, Involving Iwi in Natural Resource Management through Historical Treaty of Waitangi Settlements (2010) < http://www.lgnz.co.nz/library/files/store_024/Cabinet_decisions_treaty_ settlements_and_local_government_october_2010.pdf>

77 F Berkes, 'Evolution of Co-Management: Role of Knowledge Generation, Bridging Organizations and Social Learning' (2009) 90 Journal of Environmental Management 1692.

78 See WAI 262, above $\mathrm{n} 4$, ch 3 for a full description of all legislation and council arrangements involved.
} 
of the environment or those who live in it you harm them all. This approach is also found in other indigenous cultures and is reflected in modern discourse about sustainability.

The co-management of the Waikato River, a Māori taonga (treasure), is perhaps the best-known example of these arrangements. Co-management followed on from a settlement of the historical land claim of the Waikato-Tainui people in 2007, when the Crown signed the 'Waikato River Agreement in Principle' with Waikato-Tainui. A lengthy process of negotiation culminated in the Waikato River Settlement Act 2010. Situated in the North Island, the Waikato River is New Zealand's longest. Many towns depend on its water, and much industry, including electricity generation, is located near it. It once was a very important transportation route and the source of plentiful food. The aim of the comanagement arrangement is to restore and protect the health and wellbeing of the river for future generations. ${ }^{79}$ It allows Waikato-Tainui, who have economic and cultural relationships with the river, to be actively involved in restoring the health of the river. Māori techniques require the incorporation of Māori knowledge, cultural and social relationships, and social, cultural, and economic wellbeing in an integrated, holistic, and coordinated approach when managing the resources of the river' ${ }^{80}$ The arrangement is still young and its success, or otherwise, remains to be seen.

The WAI 262 report documents some of the impacts Māori have had on the environment, and acknowledges that some of these impacts have been damaging. But it also explains that Māori customs and practices reached an equilibrium with the environment that endured for several hundred years before Europeans arrived. The report also describes how Māori selected trees suitable for canoe paddles and carving, and how principles that protected the timber resources were observed. One witness in the claim gave evidence ${ }^{81}$

... about the system for managing native forests, based around strict selection and the minimisation of waste. For example, the wood from the pāhautea (New Zealand cedar) was both soft and longlasting, and was therefore reserved for specific limited uses. Except for making paddles and repairing boats, that type of tree would never be cut down. 'We would leave good trees to use for our next paddles.' The process for selecting the right tree to cut down for carving or other purposes was also careful and deliberate. A crucial part of this process was the karakia [prayer or incantation] to Tāne-mahuta. Mr Elkington

79 Raukawa and the Raukawa Settlement Trust and the Sovereign in right of New Zealand 'Deed in Relation to a Co-Management Framework for the Waikato River' (17 December 2009) 1.34.

80 Alex Steenstra, The Waikato River Settlement and Natural Resource Management in New Zealand $<$ http:// www.nzares.org.nz/pdf/The\%20Waikato\%20River\%20Settlement.pdf>

81 WAI 262, above n 4, 245. 
stated that this karakia was a means of 'asking for guidance' to ensure that only the correct tree would be cut down. 'We did not want to cut down the wrong tree, as that would be a waste'. This created a system for managing native forests based on the kaitiaki relationship. Similar systems were in place for the management of kaimoana [seafood]. Priscilla Paul and Jim Elkington both referred to the practice of managing and transplanting pipi, cockles, mussels, kina, pāua, oyster, and scallops for a variety of reasons, including sustainability. Transplantation was managed according to the spawning cycles of the various species, and traditional regulatory mechanisms such as rāhui [temporary ban, or ritual prohibition placed on an area or resource] were used to ensure sustainable quantities of kaimoana developed before any harvesting took place.

Another feature of indigenous innovation is the form of its expression. It is hard to avoid the pull of a technological artefact view of innovation in which new material technologies come to represent the innovative achievements of a society. If we look at the technological products of Aboriginal people prior to colonisation, they largely consist of the wooden and stone tools and hunting implements that are typical of hunter-gatherer societies. ${ }^{82}$ But different theories of innovation illuminate different dimensions of a society's achievements in innovation. The information theoretic perspective locates innovation in collective processes of generating information to reduce uncertainty. ${ }^{83}$ A society may choose to invest its resources into information that expresses itself more in services and processes than in technological artefacts. It may also emphasise the symbolic manipulation of information, meaning, amongst other things, that more time is devoted to the coding and transmission of information through story-telling, dance, ritual, art and other forms of symbolic manipulation. For Aboriginal people the sense of cosmologically derived duty to maintain a 'healthy Country' is overriding. A great many of their limited resources were devoted to generating knowledge and techniques to this end. Healthy Country would, at least in the eyes of indigenous people, represent their greatest innovative achievement. It would also have been an achievement largely lost on the colonists arriving in 1788. Indeed, evidence of Aboriginal peoples' innovation would have been seen but not recognised by the colonisers on a daily basis. Its most obvious presence was the fine-grained habitat produced by traditional methods of fire management. ${ }^{84}$

82 See Keen, above n 57, ch 3.

83 Mandeville, above $\mathrm{n} 70,49$.

84 J Russell-Smith et al, 'Contemporary Fire Regimes of Northern Australia, 1997-2001: Change Since Aboriginal Occupancy, Challenges for Sustainable Management' (2003) 12 International Journal of Wildland Fire 283. 
The innovation output of indigenous societies is best understood at the level of systems maintenance, where the systems being maintained are interlocking ecological systems and sub-systems. Whether it is using systems of mosaic burning to maintain healthy Country or systems to maintain the health of waterways, the great contribution to innovation by the indigenous peoples of Australia and New Zealand has been in developing systems to maintain the healthy functioning of environmental systems. Innovation in terms of new technological artefacts has been less of a cultural priority for Aboriginal people.

One other aspect of indigenous innovation needs to be mentioned. Some areas of innovation such as biotechnology and information technology are said to have a high degree of cumulativeness. ${ }^{85}$ In cumulative innovation, invention $\mathrm{X}$ depends on invention $\mathrm{Y}$ as an input. In a general sense, all innovation is cumulative, since no inventor invents every single input that contributes to his invention. Models of cumulative innovation operate with a narrow sense of the cumulative, looking at the sharing of rents between the first and second innovators and how IP rights affect the incentive setting. ${ }^{86}$ This has limited relevance to innovation in the indigenous setting, where it is better to think in terms of cycles of innovation dependence. In a cycle of innovation dependence, the use of one technique at one point in time allows for the more efficient or innovative use of other techniques. For example, the use of fire regimes to improve the quality and quantity of plant life offers women, who are often involved in the gathering of plants for food and medicines, more opportunities to improve the use of those plants. Along similar lines, there is clear evidence that fire regimes also increase the efficiency of small-game hunting. ${ }^{87}$ To maintain the health of a river is also to contribute to the maintenance of flora and fauna that depend on the river. In a cycle of innovation dependence, one technique or set of techniques acts as part of a set of complex conditions that help to promote other forms of innovation. The use of fire is not a direct input into the harvesting of a new plant, but it is part of a set of causal conditions that helped to promote its growth. Some sense of this complex conditionality, of which the apparently simple act (to outside observers) of setting fire to the bush is a part, can be glimpsed from the following statement:

The secret of fire in our traditional knowledge is that it is a thing that brings the land alive again. When we do burning the whole land comes alive again - it is reborn. But it is not a thing for people to play with

85 S Scotchmer, Innovation and Incentives (MIT Press, 2004) 127.

86 S Scotchmer, 'Standing on the Shoulders of Giants: Cumulative Research and the Patent Law' (1991) 5 Journal of Economic Perspectives 29.

87 R B Bird et al, "The “Fire Stick" Hypothesis: Australian Aboriginal Foraging Strategies, Biodiversity, and Anthropogenic Fire Mosaics' (2008) 105(39) Proceedings of the National Academy of Science 14796. 
unless they understand the nature of fire. ... [T] he fire-drive is itself regarded as a sacred and very serious act, often first enacted by the major creative beings for that area. ${ }^{88}$

Summing up, we can see that indigenous innovation has at least the following features. It is a place-based form of innovation depending critically on land rights for the innovators. The innovative process is deeply integrated into a cosmological connectionist scheme in which all innovation has threads leading back to ancestors. The diffusion of innovation is dependent upon use rights rather than time-limited forms of protection. The innovation system depends on the transmission of non-codified personal knowledge. While many rules surround the use of knowledge, much of this knowledge has to be learnt through personal training rather than rules. Putting it starkly, robots could not be programmed through rules to run this place-based innovation system. The goals and expression of innovation have less to do with products and everything to do with services to Country. Resources are devoted to innovation in systems maintenance, rather than to the generation of technological artefacts. This systems maintenance means that indigenous innovators operate in cycles of innovation dependence. There is a time for burning Country so that the efficiency of other techniques and practices can be improved upon.

\section{Indigenous Innovation and IP Pathways to Development}

What role, then, for IP rights in systems of indigenous innovation? It should be clear from the preceding discussion that IP rights cannot be the prime mover of indigenous innovation systems. Rather, indigenous innovation is driven by that complex web of relations that we have argued lies in the cosmological connectionism of indigenous peoples. Cosmological connectionism anchors indigenous networks to places and creates relationships of caring about those places.

In Australia, it is on Country that Aboriginal people can maintain or rebuild the institutions that support their own distinctive path to discovery. It is on Country that elders have the best chance of passing on their personal knowledge in ways that will switch on young indigenous minds to distinctive ways of observing and understanding the land and its plants and animals. Without the on-Country experience, building a distinctive indigenous human capital with the capability

88 Yibarbuk cited in M Langton, “"The Fire at the Centre of Each Family": Aboriginal Traditional Fire Regimes and the Challenges for Reproducing Ancient Fire Management in the Protected Areas of Northern Australia' (National Academics Forum: Proceedings of the 1999 Seminar, Fire! The Australian Experience 2000) 3, 7-8. 
to follow indigenous paths of discovery seems a slim prospect. The principle of co-management of resources, which we discussed earlier in the context of the management of New Zealand's rivers, is a regulatory principle that opens the door to indigenous innovation.

The systems of indigenous innovation that are being developed on Country are a mix of old and new ways of working. The cosmological framework and the duties to Country that it imposes remain invariable, but obviously there are new tools and new networks to help in the execution of those duties - helicopters to reach the remotest areas to do burning, software and data management technologies to help organise the detailed observational knowledge of Country, and networks with scientists and research institutions. Quietly some indigenous communities in Australia's north are building new capabilities with which to drive their innovation system. In chapter two of this book, David Claudie, Susan Semple, Nicholas Smith and Bradley Simpson show what is possible when indigenous innovators and scientists, each with their own path to discovery, build a common network and join their paths at the level of testing and observation. If indigenous people want to bring their innovations to markets beyond their customary ones, the networked cooperation between indigenous innovators and scientists described by Claudie, Semple, Smith and Simpson will be important.

But this also means that the locus of indigenous innovation will have to shift into a network where there are non-indigenous participants who do not see the world in terms of cosmological connectionism, at least not of the kind subscribed to by indigenous peoples. In chapter three, Jen Cleary shows that that is a frightening prospect for indigenous peoples. The participatory action research method she describes is a tool for forging these broader networks in ways that enhance indigenous peoples' chances of achieving respectful cooperation.

Much of the land controlled by Aboriginal people is characterised by ecological intactness and high biodiversity value. ${ }^{89}$ The practical problem facing indigenous communities in many places is that their innovation takes the form of services to the land that have clear public good benefits in terms of biodiversity, and environmental and climate values that are difficult to turn into income streams. Biological diversity, for example, has an economic value. Importantly, it is the stock of biodiversity, rather than individual plants, that is the source of this value..$^{90}$ Maintaining that stock is precisely the area of innovation in which indigenous systems excel. However, patent and plant variety protections

89 J C Altman, G J Buchanan and L Larsen, 'The Environmental Significance of the Indigenous Estate: Natural Resource Management as Economic Development in Remote Australia' (Discussion Paper No 286, Centre for Aboriginal Economic Policy Research, 2007) 24 <http://caepr.anu.edu.au/>

90 T Swanson and S Johnston, Global Environmental Problems and International Environmental Agreements: The Economics of International Institution Building (Edward Elgar, 1999) 65. 
allow only for the extraction of economic value from a particular product that meets the criteria of these systems (for example, the criteria of patentability for an invention). If market-based solutions to public good problems cannot be found, then the standard move is to argue that government must pay for the provision of these goods. This means government making income transfers to indigenous people for providing environmental services. This, of course, means that government must be willing to meet the fiscal and political cost of making those transfers.

So far we have been talking as if IP has no or little role in the support of indigenous innovation systems. However, this is not our position. As Tony Taubman has pointed out, the benefits of using conventional IP mechanisms to protect indigenous knowledge should not be overlooked. ${ }^{91}$ What IP can or cannot do for a given indigenous community is always context dependent. All the chapters in this book suggest that IP pathways to development might be organically constructed to suit the circumstances of a given indigenous community. However, the experience of indigenous peoples in Australia and New Zealand suggests that for the benefits of IP to be fully realised, particular conditions need to be met. The most crucial condition is progress on land rights. Once indigenous groups recover control of place, the process of creating networks to take care of place can begin. Once indigenous groups have networks in place, they can begin to enrol other actors and networks into their own to assist innovation that respects their institutions of cosmological connectionism. Chapter two in essence describes the evolution of this model of innovation. In chapter four, Daniel Robinson also provides examples of how indigenous and non-indigenous researchers can join together as an innovation network.

It is also clear from the Australian and New Zealand experience that indigenous peoples will have to work with existing institutions of IP. As we saw at the beginning of this chapter, the Australian High Court has signalled that a native title system of IP is not likely to form part of the common law's recognition of native title rights and interests. Similarly in New Zealand, the recommendations of the Waitangi Tribunal on the 262 claim signal an integrative approach of reasonable reform of IP rights over traditional knowledge. Its summary of its recommendations concerning the controversial issue of IP regulation of biological resources is emblematic of its general approach: 'All the reforms we recommend in this chapter can operate within the existing frameworks around bioprospecting, GM, and IP.' ${ }^{\prime 2}$

91 A Taubman, 'Saving the Village: Conserving Jurisprudential Diversity in the International Protection of Traditional Knowledge' in K E Maskus and J H Reichman (eds), International Public Goods and Transfer of Technology Under a Globalized Intellectual Property Regime (Cambridge University Press, 2005) 521, 534.

92 WAI 262, above n 4, 210. 
Modest incremental reform will not please everyone, but in chapter nine Miranda Forsyth suggests that new model laws may not solve very much and may open the door to destructive political contests amongst indigenous communities. Perhaps an implication of her argument is that more problems may be solved by bargaining in the shadow of imperfect IP laws than by attempting to radically rewrite them. The dissatisfied critic might reasonably reply that indigenous groups do not have enough bargaining power to secure the outcomes they want. But to some extent rules can be written that increase the negotiating power of indigenous groups when it comes to the use of their knowledge assets. The law, by creating veto rights over the use of such assets in certain circumstances, forces a negotiation that would otherwise not have occurred. The recommendations of the Waitangi Tribunal move in this general direction. For example, the Tribunal recommends the creation of a Māori Committee to work with the Commissioner of Patents on patent applications that affect Māori interests. The Tribunal also recommends the creation of a disclosure obligation for patent applicants where they have used Māori knowledge or species, with the possibility of patent invalidity for non-disclosure. Building these kinds of veto rights into IP law means that real risks attach to not entering into a process of negotiation with indigenous groups. States that are interested in fostering indigenous development networks should look to regulatory strategies that provide incentives for outsiders to negotiate with indigenous groups, and that give indigenous groups some bargaining power in those negotiations. A negotiation is an opportunity for trust to form between the parties, and it is deep trust, as Jen Cleary suggests, that will be needed in collaborations between indigenous and non-indigenous innovators.

Broadly speaking, IP rights can be divided into those that confer origination rights over a product (for example, patents and plant variety protection) and those which confer rights to distinguish a product in commerce (for example, trade marks, certification marks and geographical indications). Taken together, the chapters in this book suggest that indigenous peoples are most likely to build IP development pathways using systems that confer rights to distinguish their product in the marketplace. For reasons that Daphne Zografos Johnsson outlines in chapter seven, these systems do not offer indigenous groups comprehensive protection. They were, after all, not designed by them, but emerge out of capitalist economies. Still, the rise of ethical consumerism offers the possibility of linking products and services of indigenous innovation with consumers who are willing to pay a premium for those services and products. Every day millions of consumers around the world pay more for products that bear the fairtrade certification mark of the Fairtrade Labelling Organizations International because the mark represents a system made up of standards and fairtrade prices aimed at promoting the sustainable development of poor producers in developing countries. The evolution of this system in the context 
of protected agricultural markets and complex multinational supply networks is a remarkable story. ${ }^{93}$ Along similar lines, one can imagine consumers being willing to pay for products produced on Country under indigenous fire management practices that helped to reduce Australia's carbon emissions. ${ }^{94}$ In chapter five Christoph Graber and Jessica Lai draw together the lessons from the failure of Australia's national certification scheme for indigenous products, and present the case for why a globally recognised certification scheme might be the way forward.

The use of geographical indications (GIs) in the context of indigenous innovation is perhaps less obvious, given that they are less flexible than voluntary certification systems. But in chapter six Daniel Gervais builds an eloquent case for the possibilities. If GIs are to have a Foucaldian moment of creation in which they truly serve the indigenous collective, then it will have to be along the lines for which he argues. ${ }^{95}$ In chapter eight Michael Blakeney reminds us of the hard geo-political trade reality of IP. He shows the connections between the EU agenda on GIs and its broader trade agenda on agriculture. His chapter is also a reminder that so much IP standard-setting now takes place in the crucible of trade agreements - a crucible that is hard for indigenous groups to penetrate and influence. One wonders, for example, whether Australia's trade negotiators consulted indigenous people in the context of the US-Australia Free Trade Agreement.

This opening chapter has suggested that a commodity regime like the patent system does not fit particularly well with innovation in systems that characterise much of indigenous innovation. For example, the techniques of indigenous fire management have a wide range of ecological benefits, including the reduction of carbon emissions through the reduced severity of late-season savannah fires in Northern Australia. ${ }^{96}$ Capturing the value that these techniques generate depends more on government catalysing carbon markets in ways that allow for indigenous participation than it does on one indigenous group embarking on the fruitless task of trying to gain a monopoly over a method of burning

93 For an excellent account see A Hutchens, Changing Big Business: The Globalisation of the Fair Trade Movement (Edward Elgar, 2009).

94 For a study that examines the possibilities of fair trade in Australia see M Spencer and J Hardie, Indigenous Fair Trade in Australia: Scoping Study (Rural Industries Research and Development Corporation Publication No 10/172, 2011).

95 However, developing a GI requires the networked engagement of governmental actors. For a case study that shows the intensive networking demands of GIs see D Rangnekar, 'Geographical Indications and Localisation: A Case Study of Feni' (Research Report, Economic and Social Research Council, The University of Warwick, 2009). A GI system can have a lock-in effect when it comes to traditional methods of production, acting as an incentive against innovation. See W van Caenegem, 'Registered Geographical Indications: Between Intellectual Property and Rural Policy — Part I' (2003) 6 Journal of World Intellectual Property 699. See also S Frankel ‘The Mismatch of Geographical Indications and Innovative Traditional Knowledge' (2011) 29(3) Prometheus 253.

96 For a full discussion of the benefits see Russell-Smith et al, above $\mathrm{n} 73$. 
that has been collectively practised by indigenous people in Australia for thousands of years. Moreover, in the unlikely event that a single group was able to persuade a busy patent examiner in the Australian patent office that this really was an invention and not part of the prior art, the grant of such a patent would be the worst possible outcome for both indigenous and non-indigenous Australians. Other indigenous groups would ask why one group should gain a monopoly over techniques that had been collectively developed and practised by indigenous people for such a long time. The patent system is a winner-takeall system that has huge potential to divide indigenous communities. Daniel Robinson's discussion of biopiracy in chapter four shows how the patent system struggles to maintain standards of novelty and inventiveness that meaningfully engage with innovation. Some indigenous people may, of course, want to take advantage of these low standards to obtain patents for themselves, but they are likely more often than not to be the victims rather than the beneficiaries of the patent system's low standards.

Perhaps the most important thing for indigenous innovation is to make 'indigenous innovation' rather than traditional knowledge the primary term of art in this field. Then policy-makers would have to start asking how they might support indigenous innovation, as opposed to dividing the spoils from traditional knowledge. Answering that question would lead to others. How might we encourage collaboration between cosmologically anchored indigenous networks and scientific networks? How might we intervene in the IP system to increase the bargaining power of indigenous innovators? What can we do to turn indigenous networks into development networks? One suspects this approach would lead to a more testing but ultimately richer world for science, and a better world for indigenous people in which they would gain the respect that comes from being seen as innovators. 